\title{
Statewide HPV Vaccine Initiation Among Adolescent Females in North Carolina
}

\author{
Paul L. Reiter, $\mathrm{PhD}^{*}+\dagger$, Joan R. Cates, $\mathrm{PhD}^{\ddagger}$, Annie-Laurie McRee, MPH${ }^{\star}$, Sami L. Gottlieb, \\ MD§, Autumn Shafer, MA ${ }^{\ddagger}$, Jennifer S. Smith, $\mathbf{P h D}^{\star}, \dagger$, and Noel T Brewer, $\mathbf{P h D}^{\star}, \dagger$ \\ *Department of Health Behavior and Health Education, UNC Gillings School of Global Public \\ Health, Chapel Hill, NC \\ †Lineberger Comprehensive Cancer Center, Chapel Hill, NC \\ FUNC School of Journalism and Mass Communication, Chapel Hill, NC \\ $\S$ Centers for Disease Control and Prevention, Atlanta, GA
}

\begin{abstract}
Background-Cervical cancer incidence in the United States may be greatly reduced through widespread human papillomavirus (HPV) vaccination. We estimated the statewide level of HPV vaccine initiation among adolescent girls in North Carolina and identified correlates of vaccine initiation.
\end{abstract}

Methods-We used data from 617 parents of adolescent females from North Carolina who completed the population-based 2008 Child Health Assessment and Monitoring Program survey. Analyses used weighted multivariate logistic regression.

Results-Overall, $31.3 \%$ of parents reported their daughters had received at least 1 dose of HPV vaccine. Vaccine initiation was higher among daughters aged 13 to 15 years (odds ratio [OR] = $2.03,95 \% \mathrm{CI}, 1.12-3.67$ ) or 16 to 17 years $(\mathrm{OR}=3.21,95 \% \mathrm{CI}, 1.76-5.86)$ compared with those 10 to 12 years old. Additional correlates of HPV vaccine initiation included the daughter having a preventive check-up in the last 12 months ( $\mathrm{OR}=5.09,95 \% \mathrm{CI}, 2.43-10.67)$, having received meningococcal vaccine $(\mathrm{OR}=2.50,95 \% \mathrm{CI}, 1.55-4.01)$, or being from an urban area $(\mathrm{OR}=1.81$, 95\% CI, 1.02-3.21). Among parents of unvaccinated daughters, intent to vaccinate in the next year was higher among those with daughters aged 13 to 17 years. Parents of unvaccinated non-Hispanic white daughters reported lower levels of intent to vaccinate within the next year compared with parents of unvaccinated daughters of other races.

Conclusions-HPV vaccine initiation in North Carolina is comparable with other US areas. Potential strategies for increasing HPV vaccination levels include reducing missed opportunities

Copyright () 2010 American Sexually Transmitted Diseases Association All rights reserved.

Correspondence: Paul L. Reiter, PhD, Department of Health Behavior and Health Education, UNC Gillings School of Global Public Health, 323D Rosenau Hall, CB 7440, Chapel Hill, NC 27599-7440. preiter@email.unc.edu. Noel T. Brewer, PhD, UNC Gillings School of Global Public Health, Department of Health Behavior and Health Education, 325 Rosenau Hall, CN 7440, Chapel Hill, NC 27599-7440.ntb1@unc.edu.

Although we do not believe we have any conflicts of interest, we wish to share the following information in the interest of full disclosure. 
for HPV vaccination at preventive check-ups and increasing concomitant administration of HPV vaccine with other adolescent vaccines.

Human papillomavirus (HPV) is an extremely common sexually transmitted infection among women in the United States, ${ }^{1,2}$ with infection often occurring soon after sexual debut. ${ }^{3}$ While most HPV infections spontaneously clear within 1 year, ${ }^{4-6}$ women with persistent infections face a higher risk of developing cervical disease. Oncogenic HPV types are responsible for virtually all cases of cervical cancer, with types 16 and 18 accounting for approximately $70 \%$ of these cancers. ${ }^{7,8}$ In 2009 , there will be an estimated 11,270 incident cases of cervical cancer in the United States. ${ }^{9}$ Nononcogenic HPV types 6 and 11 are associated with more than $90 \%$ of cases of anogenital warts, ${ }^{10}$ which affect approximately $7 \%$ of sexually active females. ${ }^{11}$

The US Food and Drug Administration licensed a quadrivalent HPV vaccine for use in June 2006 to protect against types 6, 11, 16, and 18. The US Advisory Committee on Immunization Practices currently recommends the 3-dose vaccine regimen be administered routinely to all females aged 11 to 12 years, but the vaccine may be administered as early as age 9, with catch-up vaccination for females ages 13 to $26 .{ }^{12}$ If widespread vaccination is achieved, cervical cancer incidence may be greatly reduced, perhaps by as much as $77 \%{ }^{8}$

Recent data from the 2008 National Immunization Survey-Teen found that $37 \%$ of female adolescents aged 13 to 17 years in the United States had received 1 or more doses of HPV vaccine. ${ }^{13}$ Although a few studies have identified correlates of HPV vaccine acceptability among statewide samples, ${ }^{14,15}$ no study, to our knowledge, has used statewide data to estimate HPV vaccine initiation and identify correlates of initiation among adolescent girls. We aimed to generate a population-based estimate of HPV vaccine initiation among adolescent females from North Carolina. We also sought to examine potential correlates of vaccine initiation, including characteristics of adolescent females, their caregivers, households, and counties of residence.

\section{MATERIALS AND METHODS}

\section{Study Design}

This study used data on North Carolina residents from the 2008 Behavioral Risk Factor Surveillance System (BRFSS) and 2008 Child Health Assessment and Monitoring Program (CHAMP) surveys. BRFSS is an annual, population-based telephone survey of healthrelated behaviors among noninstitutionalized adults 18 years and older in the United States. ${ }^{16}$ The North Carolina State Center for Health Statistics (SCHS) Survey Center uses random-digit-dialing and a computer-assisted-telephone-interviewing system to conduct BRFSS surveys. Additional information on BRFSS design and methodology is available through the Centers for Disease Control and Prevention. ${ }^{16}$

The SCHS also conducts the CHAMP survey annually to measure the health characteristics of children in North Carolina less than 18 years old. Interviewers asked adults completing the BRFSS interview if any children less than 18 years of age lived in their household. For those with a child in their household, interviewers asked about the child's date of birth, 
gender, and whether the respondent would complete the CHAMP survey about the child's health. If a respondent agreed to participate, an interviewer placed a follow-up call about 2 weeks later to complete the survey with the person identified as being the most knowledgeable about the child's health (usually the BRFSS respondent). A preprogrammed process in the computer- assisted-telephone-interviewing system randomly selected one child to be the index child for the CHAMP survey in households with more than one child under the age of 18. We paid to have the CHAMP survey include a section on HPV vaccination, administered to caregivers whose index child was a female 10 to 17 years of age. To use caregiver data from the BRFSS survey, we linked data from CHAMP and BRFSS surveys using a unique identifier.

The response rate for the 2008 BRFSS survey in North Carolina was $60.6 \% .{ }^{17}$ In total, 3865 of 4565 (84.7\%) eligible BRFSS households agreed to participate in the CHAMP survey, of which $2987(77.3 \%)$ completed the survey. All caregivers $(n=700)$ with age-eligible daughters who completed the CHAMP survey received HPV vaccine items. Of these, 68 caregivers were not asked about vaccine initiation because they had not heard of HPV vaccine before the survey (or were unsure if they had heard of it), and 15 either refused to provide HPV vaccine initiation information or indicated they did not know if their female child had received HPV vaccine. We report data on HPV vaccine initiation for the remaining 617 female adolescents, as reported by their caregivers. Since most caregivers (94\%; 581/617) reported being a parent of the female child, we refer to them as "parents" and the female children as "daughters." Of parents completing the CHAMP survey, 81\% (502/617) were the original BRFSS respondents. The Institutional Review Board at the University of North Carolina determined that this study did not require Institutional Review Board approval.

\section{Measures}

The CHAMP survey assessed HPV vaccine initiation, the main study outcome, using the item "Has (daughter's name) had any shots of the HPV vaccine?" Because the survey did not collect data on the number of vaccine doses received, we focus on vaccine initiation of having received at least 1 dose, although we acknowledge that 3 doses are required for full vaccine effectiveness. The CHAMP survey also collected information on where the daughter received HPV vaccine.

Interviewers asked parents of unvaccinated females the main reason why they had not initiated HPV vaccine for their daughters. Many parents indicated multiple reasons, all of which interviewers recorded. The survey collected data on whether parents of unvaccinated females intended to get their daughter HPV vaccine in the next year with the item "How likely are you to get the HPV vaccine for (daughter's name) in the next 12 months?" Response options (coded 1-4) were "definitely won't," "probably won't," "probably will," and "definitely will." We recoded responses of "don't know/not sure" to the midpoint of the scale.

Interviewers assessed daughter's age, race/ethnicity (non-Hispanic white, non-Hispanic black, or other [including Hispanic]), school type, and healthcare coverage during the CHAMP survey. Parents indicated whether their daughters have a regular healthcare 
provider, had a preventive check-up in the last 12 months, and received meningococcal vaccine. Interviewers also collected data during the CHAMP survey regarding how often parents thought children should be seen by a healthcare provider for a regular check-up and highest education level completed by anyone in the household.

During the BRFSS survey, parents provided information regarding demographics and whether they had received influenza vaccine (either shot or spray) for themselves in the last year. Female respondents indicated when their last Pap smear test was and whether they had received HPV vaccine for themselves (asked only to females aged 18-49 years).

Interviewers also asked each parent for county of residence, from which geographic region within North Carolina (Eastern, Piedmont [central], or Western) was determined. We also classified households as "urban" (in a metropolitan statistical area) or "rural" (outside of an metropolitan statistical area) based on residence location. ${ }^{18}$

For use in analyses, we separately gathered data on characteristics of counties where respondents lived. Demographic variables based on Census 2000 data included percent of population within each county aged 5 to 17 years, percent aged 25 years and older who were high school graduates (or had higher education), percent minority female, and percent who spoke a language other than English in the home. ${ }^{19}$ We obtained data from the SCHS on the percent of population within each county living below the federal poverty level and the number of persons per healthcare professional. ${ }^{20}$ The SCHS also provided data on ageadjusted 10-year cervical cancer incidence and mortality rates (1997-2006), as well as teen pregnancy rates (2005-2007). For 8 counties whose incidence rates were unavailable due to a small number of cases, we used the lowest reported 10-year incidence rate among the counties.

\section{Data Analysis}

We used logistic regression models to identify bivariate correlates of HPV vaccine initiation. We then entered statistically significant bivariate predictors $(P<0.05)$ into a multivariate logistic regression model. Among parents of unvaccinated females, we used linear regression to determine if intent to vaccinate within the next year differed by demographic factors thought to be important to HPV vaccine initiation (daughter's age ${ }^{21}$ ) or cervical cancer incidence (daughter's race ${ }^{22}$ and urbanicity ${ }^{23}$ ). Analyses applied sampling weights to account for the study design, though frequencies are not weighted. Statistical tests using Intercooled Stata Version 10.1 (College Station, TX) were 2-tailed with a critical a of 0.05.

\section{RESULTS}

\section{Participant Characteristics}

The daughters' mean age was 13.6 (standard deviation $[\mathrm{SD}]=2.4$ ) years old, with comparable numbers across all 3 age groups (10-12, 13-15, and 16-17 years old) (Table 1). Most parents reported their daughters attended a public school (87.9\%), had some form of healthcare coverage (95.0\%), had a regular healthcare provider (85.8\%), and had received a preventive check-up within the last year $(81.3 \%)$. A majority of parents indicated their daughters were non-Hispanic white (67.6\%) or non-Hispanic black (20.3\%), with fewer 
indicating their daughters were another race or ethnicity $(12.0 \%$, including Hispanic $[\mathrm{n}=35$, $6.7 \%])$.

A majority of parents were of age 40 or older (68.4\%), female (83.2\%), married or member of an unmarried couple (76.5\%), and employed (68.7\%). Most households had an income of $\$ 50,000$ or more $(56.7 \%)$, contained a person with at least some college education $(81.5 \%)$, and were located in an urban area $(70.4 \%)$.

\section{HPV Vaccine Initiation}

Overall, 198 of 617 (31.3\%, 95\% confidence interval [CI]: 26.8\%-36.1\%) of parents reported their daughters had received at least 1 dose of HPV vaccine. Among those who reported vaccine initiation, most parents indicated that their daughters received HPV vaccine from either their family doctors/general practitioners $(58.1 \%)$ or pediatricians $(33.6 \%)$. Few parents reported obtaining vaccine from public or community clinics (3.9\%), obstetriciangynecologists $(1.6 \%)$, or elsewhere $(2.9 \%)$.

HPV vaccination was far less common among daughters aged 10 to 12 years (18.8\%) compared with daughters aged 13 to 15 years $(33.2 \%)$ or 16 to 17 years (45.2\%) (both $P<$ 0.05 in bivariate analyses). Vaccine initiation was also higher in bivariate analyses among daughters who had a regular healthcare provider, had a preventive check-up in the last 12 months, had received meningococcal vaccine, lived in an urban area, or resided in counties with higher percentages of the population who spoke a language other than English in their home (all $P<0.05$ ) (Tables 2 and 3). Parents who were currently employed or reported receiving flu vaccine in the last year for themselves were more likely to report HPV vaccine initiation (both $P<0.05$ ).

In multivariate analyses (Table 4), vaccine initiation was higher among daughters who were 13 to 15 years old (odds ratio $[\mathrm{OR}]=2.03,95 \% \mathrm{CI}, 1.12-3.67$ ) or 16 to 17 years old (OR = $3.21,95 \%$ CI, $1.76-5.86)$, had a preventive check-up in the last 12 months ( $\mathrm{OR}=5.09,95 \%$ CI, 2.43-10.67), had received meningococcal vaccine (OR $=2.50,95 \% \mathrm{CI}, 1.55-4.01)$, or were from an urban area $(\mathrm{OR}=1.81,95 \% \mathrm{CI}, 1.02-3.21)$. Parents were also more likely to report HPV vaccine initiation among their daughters if they had received flu vaccine in the last year for themselves $(\mathrm{OR}=2.03,95 \% \mathrm{CI}, 1.26-3.26)$.

\section{Reasons for Not Vaccinating and Intentions to Vaccinate}

Among parents of unvaccinated daughters $(n=419)$, the most commonly reported reasons for not vaccinating was not knowing enough or needing more information about the vaccine (20.8\%) and believing their child was too young for HPV vaccine (20.4\%). Other frequently indicated reasons included concerns about vaccine safety or side effects (13.4\%), believing the vaccine was too new (12.7\%), not having a healthcare provider recommend the vaccine (12.7\%), and reporting their daughter was not sexually active yet $(5.1 \%)$. All other reasons were reported by less than $5 \%$ of parents. Interestingly, only $0.6 \%(\mathrm{n}=3)$ of parents reported their daughters had not received HPV vaccine yet because the vaccine might promote sexual activity. 
Parents of unvaccinated daughters expressed only moderate intent to get their daughters HPV vaccine within the next year $($ mean $=2.39, \mathrm{SD}=1.01)(42.3 \%, 173 / 419$ indicated "probably will" or "definitely will"). Compared with parents of unvaccinated daughters aged 10 to 12 years, parents of unvaccinated daughters aged 13 to 15 years $(2.52 \mathrm{vs.} 2.20, t=$ $2.34, P=0.019)$ or 16 to 17 years ( 2.54 vs. $2.20, t=2.34, P=0.019$ ) reported higher levels of intent to vaccinate in the next year. Intent did not differ between parents of unvaccinated daughters in the 2 older age groups $(P=0.874)$. Parents of unvaccinated non-Hispanic white daughters reported similar levels of intent compared with parents of unvaccinated nonHispanic black daughters ( 2.28 vs. $2.47, t=-1,31, P=0.190$ ), but lower levels of intent compared with parents of unvaccinated daughters of other races (2.28 vs. $2.79, t=-2.98, P$ $=0.003)$. Intent did not differ between parents of unvaccinated non-Hispanic black daughters and parents of unvaccinated daughters in other racial groups $(P=0.099)$. Intent levels among parents of unvaccinated daughters in urban areas did not differ from those in rural areas (2.36 vs. $2.43, t=-0.55, P=0.580)$.

\section{DISCUSSION}

If widespread HPV vaccination is achieved in the United States, cervical cancer incidence may be greatly reduced. ${ }^{8}$ Among a statewide sample of North Carolina parents, we found less than a third reported their adolescent daughters had received any doses of HPV vaccine. While this estimate is much lower than that of nations with school-based HPV vaccine programs, ${ }^{24,25}$ it is only slightly below the national average among adolescent females from the United States in $2008 .{ }^{13}$ Our previous study involving 5 counties in North Carolina reported only $10 \%$ of similarly aged adolescent females had initiated the HPV vaccine regimen in 2007. ${ }^{21}$ Thus, HPV vaccine initiation among adolescent females appears to be increasing as time since HPV vaccine licensure passes.

HPV vaccination likely offers the greatest benefit if administered before sexual debut. ${ }^{12,26}$ However, both HPV vaccine initiation and parents' intent to vaccinate within the next year were lower for younger daughters, including those in the recommended age range for vaccination (11-12 years). ${ }^{12}$ Our results coincide with previous findings regarding vaccine initiation ${ }^{21,27}$ and intentions. ${ }^{28,29}$ Although most older adolescent females (aged 14-19 years) are seronegative for all HPV types contained in the quadrivalent HPV vaccine ${ }^{30}$ and may therefore still derive full benefit from the vaccine, future efforts should still consider targeting younger females for HPV vaccination. Almost half of females in the United States are sexually active during high school, ${ }^{31}$ and about $9 \%$ of females aged 14 to 19 years have serologic evidence of infection with at least $1 \mathrm{HPV}$ type contained in the quadrivalent vaccine. ${ }^{30}$ Furthermore, analyses have shown that the cost-effectiveness of HPV vaccination is optimized when there is high vaccination coverage among younger adolescent females. ${ }^{32}$

Vaccine initiation was higher among females from urban areas, which is concerning since women in rural areas have higher cervical cancer incidence rates. ${ }^{23}$ Although we did not find lower HPV vaccine coverage in rural areas previously, ${ }^{21}$ this study was conducted among 5 counties clustered in the same geographic area. Residents of rural areas may face additional barriers to receiving healthcare, including HPV vaccine, such as fewer healthcare 
providers and having to travel longer distances to healthcare. ${ }^{33,34}$ Rural residents represent an important target population for future HPV vaccine research.

With cervical cancer incidence rates higher among blacks, ${ }^{22}$ it is encouraging that they had similar levels of HPV vaccine initiation as non-Hispanic whites. Such findings are promising in that HPV vaccine may help reduce the existing cervical cancer racial disparities. We do wish to note that in exploratory analyses, daughters identified as Hispanic had lower levels of vaccine initiation compared with all other racial groups $(P<0.05$; data not shown), though further analyses were not conducted due to the small number of vaccinated Hispanic daughters $(n=5)$. While parents of unvaccinated Hispanic daughters reported high intentions to vaccinate in the next year (data not shown), future research addressing HPV vaccination among Hispanics is warranted.

The strongest correlate of HPV vaccine initiation was parents reporting their daughter had a preventive check-up in the last year. One potential reason for this finding is that a healthcare provider recommended HPV vaccination during the check-up, as provider's recommendation has been correlated with vaccine initiation previously. ${ }^{21,35}$ Only $36.3 \%$ of parents who indicated their daughter had a preventive check-up in the last year, however, also reported HPV vaccine initiation, suggesting there are still many missed opportunities by healthcare providers to encourage and administer HPV vaccine to adolescent females during these check-ups.

Parents were more likely to report their daughter had received HPV vaccine if they had also received meningococcal vaccine. Although data were not available concerning the temporality of receiving these vaccines, results underscore the potential to increase HPV vaccine initiation by administering it concomitantly with other adolescent vaccines. Because HPV vaccine has no components that might adversely affect safety or efficacy of other vaccines, the Advisory Committee on Immunization Practices currently states that HPV vaccine can be administered at the same visit as other adolescent vaccines, and that doing so increases the likelihood that adolescents will receive each vaccine on schedule. ${ }^{12}$

The association observed between parental flu vaccination and HPV vaccination among daughters may result from parents who receive flu vaccine utilizing health services for themselves and their families more frequently. It is also possible that these parents have a higher level of acceptance for vaccines in general.

Our study has several important strengths including a large, population-based sample of parents and examining a wide range of potential correlates of HPV vaccine initiation. The BRFSS and CHAMP surveys had good response rates and the capability to conduct interviews in Spanish. In addition to being a cross-sectional study, there were other study limitations. A different person, in some instances, was interviewed for the BRFSS and CHAMP surveys. We relied solely upon parental reports of vaccination, though we found the same level of HPV vaccine initiation as the state-specific estimate from the 2008 National Immunization Survey-Teen for North Carolina, which uses provider-verified vaccination records. ${ }^{13}$ Some constructs that may be important to HPV vaccination, such as 
religious affiliation, ${ }^{36}$ were not measured in this research. Only parents who had a land line telephone were interviewed, and the generalizability of the findings is not yet known.

In a statewide sample of North Carolina parents, just under one-third reported their daughters had received one more doses of HPV vaccine. This level of vaccination coverage is comparable with other recent estimates of HPV vaccination in the United States, yet remains far lower than those observed in some other developed nations. Reducing missed opportunities for vaccination at preventive check-ups and increasing concomitant administration of adolescent vaccines may help increase HPV vaccination levels in the United States.

\section{Acknowledgments}

The authors thank the North Carolina State Center for Health Statistics for their assistance.

Supported by the Centers for Disease Control and Prevention (S3715-25/25), the American Cancer Society (MSRG-06-259-01-CPPB), and the Cancer Control Education Program at Lineberger Comprehensive Cancer Center (R25 CA57726).

N.T.B. received a research grant from Merck \& Co., Inc. for a study in 2008-2009 of men's attitudes toward HPV vaccination. N.T.B. has received no honoraria or consulting fees from Merck \& Co., Inc. or GlaxoSmithKline. J.S.S. has received research grants or contracts, honoraria, or consulting fees during the last 4 years from GlaxoSmithKline and Merck \& Co., Inc. No funds from Glaxo-SmithKline or Merck \& Co., Inc. funded these research activities.

\section{REFERENCES}

1. Dunne EF, Unger ER, Sternberg M, et al. Prevalence of HPV infection among females in the United States. JAMA. 2007; 297:813-819. [PubMed: 17327523]

2. Weinstock H, Berman S, Cates W Jr. Sexually transmitted diseases among American youth: Incidence and prevalence estimates, 2000. Perspect Sex Reprod Health. 2004; 36:6-10. [PubMed: 14982671]

3. Winer RL, Lee SK, Hughes JP, et al. Genital human papillomavirus infection: Incidence and risk factors in a cohort of female University students. Am J Epidemiol. 2003; 157:218-226. [PubMed: 12543621]

4. Moscicki AB, Shiboski S, Broering J, et al. The natural history of human papillomavirus infection as measured by repeated DNA testing in adolescent and young women. J Pediatr. 1998; 132:277284. [PubMed: 9506641]

5. Franco EL, Villa LL, Sobrinho JP, et al. Epidemiology of acquisition and clearance of cervical human papillomavirus infection in women from a high-risk area for cervical cancer. J Infect Dis. 1999; 180:1415-1423. [PubMed: 10515798]

6. Ho GY, Bierman R, Beardsley L, et al. Natural history of cervicovaginal papillomavirus infection in young women. N Engl J Med. 1998; 338:423-428. [PubMed: 9459645]

7. Bosch FX, de Sanjose S. Chapter 1: Human papillomavirus and cervical cancer-burden and assessment of causality. J Natl Cancer Inst Monogr. 2003; 31:3-13. [PubMed: 12807939]

8. Smith JS, Lindsay L, Hoots B, et al. Human papillomavirus type distribution in invasive cervical cancer and high-grade cervical lesions: A meta-analysis update. Int J Cancer. 2007; 121:621-632. [PubMed: 17405118]

9. American Cancer Society. Cancer Facts and Figures, 2009. Atlanta, GA: American Cancer Society; 2009.

10. Greer CE, Wheeler CM, Ladner MB, et al. Human papillomavirus (HPV) type distribution and serological response to HPV type 6 virus-like particles in patients with genital warts. J Clin Microbiol. 1995; 33:2058-2063. [PubMed: 7559948] 
11. Dinh TH, Sternberg M, Dunne EF, et al. Genital warts among 18- to 59-year-olds in the United States, National Health and Nutrition Examination Survey, 1999-2004. Sex Transm Dis. 2008; 35:357-360. [PubMed: 18360316]

12. Markowitz LE, Dunne EF, Saraiya M, et al. Quadrivalent human papillomavirus vaccine: Recommendations of the Advisory Committee on Immunization Practices (ACIP). MMWR Recomm Rep. 2007; 56(RR-2):1-24. [PubMed: 17380109]

13. Centers for Disease Control and Prevention (CDC). National, state, and local area vaccination coverage among adolescents aged 13-17 years-United States, 2008. MMWR Morb Mortal Wkly Rep. 2009; 58:997-1001. [PubMed: 19763075]

14. Christian WJ, Christian A, Hopenhayn C. Acceptance of the HPV vaccine for adolescent girls: Analysis of state-added questions from the BRFSS. J Adolesc Health. 2009; 44:437-445. [PubMed: 19380090]

15. Constantine NA, Jerman P. Acceptance of human papillomavirus vaccination among Californian parents of daughters: A representative statewide analysis. J Adolesc Health. 2007; 40:108-115. [PubMed: 17259050]

16. Centers for Disease Control and Prevention. Behavioral Risk Factor Surveillance System Survey. Atlanta, GA: Department of Health and Human Services, Centers for Disease Control and Prevention; 2008.

17. Centers for Disease Control and Prevention. Behavioral Risk Factor Surveillance System 2008 Summary Data Quality Report. Available at: ftp://ftp.cdc.gov/pub/Data/Brfss/ 2008_Summary_Data_Quality_Report.pdf.

18. U.S. Census Bureau. Metropolitan and micropolitan statistical areas. Available at: http:// www.census.gov/population/www/metroareas/metroarea.html.

19. U.S. Census Bureau. American FactFinder, Census 2000. Available at: http://www.census.gov/.

20. North Carolina State Center for Health Statistics. North Carolina health statistics pocket guide 2007. Available at: http://www.schs.state.nc.us/SCHS/data/pocketguide/2007/index.html.

21. Gottlieb SL, Brewer NT, Sternberg MR, et al. Human papillomavirus vaccine initiation in an area with elevated rates of cervical cancer. J Adolesc Health. 2009; 45:430-437. [PubMed: 19837348]

22. Watson M, Saraiya M, Benard V, et al. Burden of cervical cancer in the United States, 1998-2003. Cancer. 2008; 113(suppl 10):2855-2864. [PubMed: 18980204]

23. Benard VB, Coughlin SS, Thompson T, et al. Cervical cancer incidence in the United States by area of residence, 1998 2001. Obstet Gynecol. 2007; 110:681-686. [PubMed: 17766618]

24. Shefer A, Markowitz L, Deeks S, et al. Early experience with human papillomavirus vaccine introduction in the United States, Canada and Australia. Vaccine. 2008; 26(suppl 10):K68-K75. [PubMed: 18847559]

25. Brabin L, Roberts SA, Stretch R, et al. Uptake of first two doses of human papillomavirus vaccine by adolescent schoolgirls in Manchester: Prospective cohort study. BMJ. 2008; 336:1056-1058. [PubMed: 18436917]

26. Hildesheim A, Herrero R. Human papillomavirus vaccine should be given before sexual debut for maximum benefit. J Infect Dis. 2007; 196:1431-1432. [PubMed: 18008218]

27. Chao C, Slezak JM, Coleman KJ, et al. Papanicolaou screening behavior in mothers and human papillomavirus vaccine uptake in adolescent girls. Am J Public Health. 2009; 99:1137-1142. [PubMed: 19372507]

28. Brewer NT, Fazekas KI. Predictors of HPV vaccine acceptability: A theory-informed, systematic review. Prev Med. 2007; 45:107-114. [PubMed: 17628649]

29. Kahn JA, Ding L, Huang B, et al. Mothers' intention for their daughters and themselves to receive the human papillomavirus vaccine: A national study of nurses. Pediatrics. 2009; 123:1439-1445. [PubMed: 19482752]

30. Markowitz LE, Sternberg M, Dunne EF, et al. Seroprevalence of human papillomavirus types 6, 11, 16, and 18 in the United States: National Health and Nutrition Examination Survey 20032004. J Infect Dis. 2009; 200:1059-1067. [PubMed: 19719390]

31. Eaton DK, Kann L, Kinchen S, et al. Youth risk behavior surveillance-United States, 2005. MMWR Surveill Summ. 2006; 55:1-108. [PubMed: 16760893] 
32. Kim JJ, Goldie SJ. Health and economic implications of HPV vaccination in the United States. N Engl J Med. 2008; 359:821-832. [PubMed: 18716299]

33. Arcury TA, Gesler WM, Preisser JS, et al. The effects of geography and spatial behavior on health care utilization among the residents of a rural region. Health Serv Res. 2005; 40:135-155. [PubMed: 15663706]

34. Katz ML, Wewers ME, Single N, et al. Key informants' perspectives prior to beginning a cervical cancer study in Ohio Appalachia. Qual Health Res. 2007; 17:131-141. [PubMed: 17170251]

35. Reiter PL, Brewer NT, Gottlieb SL, et al. Parents' health beliefs and HPV vaccination of their adolescent daughters. Soc Sci Med. 2009; 69:475-480. [PubMed: 19540642]

36. Brewer, NT.; Gottlieb, SL.; Reiter, PL., et al. Longitudinal predictors of HPV vaccine uptake. Paper presented by: Presented at the American Public Health Association Annual Meeting; November, 2009; Philadelphia, PA. 
TABLE 1

Characteristics of Parents and Their Daughters $(n=617)$

n $\quad$ Weighted \% $(95 \% \mathrm{CI})$

\begin{tabular}{|c|c|c|}
\hline \multicolumn{3}{|l|}{ Daughter characteristics } \\
\hline \multicolumn{3}{|l|}{ Age (yr) } \\
\hline $10-12$ & 198 & $36.9(32.1-42.0)$ \\
\hline $13-15$ & 235 & $34.7(30.2-39.5)$ \\
\hline $16-17$ & 184 & $28.4(24.2-33.0)$ \\
\hline \multicolumn{3}{|l|}{ Race } \\
\hline Non-Hispanic white & 450 & $67.6(62.7-72.3)$ \\
\hline Non-Hispanic black & 89 & $20.3(16.3-25.0)$ \\
\hline Other & 78 & $12.0(9.2-15.6)$ \\
\hline \multicolumn{3}{|l|}{ School type ${ }^{*}$} \\
\hline Public & 544 & $87.9(84.2-90.8)$ \\
\hline Private/home schooled & 69 & $12.1(9.2-15.8)$ \\
\hline \multicolumn{3}{|l|}{ Healthcare coverage } \\
\hline No & 33 & $5.0(3.2-7.6)$ \\
\hline Yes & 584 & $95.0(92.4-96.8)$ \\
\hline \multicolumn{3}{|l|}{ Regular healthcare provider } \\
\hline No/don't know & 90 & $14.2(11.2-18.0)$ \\
\hline Yes & 527 & $85.8(82.0-88.8)$ \\
\hline \multicolumn{3}{|l|}{ Preventive check-up in last 12 mo } \\
\hline No/don't know & 120 & $18.7(15.2-22.8)$ \\
\hline Yes & 497 & $81.3(77.2-84.8)$ \\
\hline \multicolumn{3}{|l|}{ Parent characteristics } \\
\hline \multicolumn{3}{|l|}{$\operatorname{Age}(\mathrm{yr})^{\dagger}$} \\
\hline$\leq 39$ & 164 & $31.6(27.0-36.6)$ \\
\hline $40-49$ & 303 & $48.9(43.9-53.8)$ \\
\hline 250 & 150 & $19.5(16.1-23.5)$ \\
\hline \multicolumn{3}{|l|}{ Sex } \\
\hline Female & 513 & $83.2(79.1-86.6)$ \\
\hline Male & 104 & $16.8(13.4-20.9)$ \\
\hline \multicolumn{3}{|l|}{ Marital status ${ }^{\dagger}$} \\
\hline Married/member of unmarried couple & 474 & $76.5(72.0-80.4)$ \\
\hline Other (divorced, widowed, separated, never married) & 143 & $23.5(19.6-28.0)$ \\
\hline \multicolumn{3}{|l|}{ Employment status ${ }^{\dagger}$} \\
\hline Employed for wages/self-employed & 448 & $68.7(63.7-73.2)$ \\
\hline Other (unemployed, homemaker, student, retired, unable to work) & 169 & $31.3(26.8-36.3)$ \\
\hline \multicolumn{3}{|l|}{ Household characteristics } \\
\hline \multicolumn{3}{|l|}{ Annual household income ${ }^{\dagger}$} \\
\hline$<\$ 50,000$ & 231 & $35.5(31.0-40.4)$ \\
\hline
\end{tabular}




\begin{tabular}{lrc}
\hline & $\mathbf{n}$ & Weighted \% (95\% CI) \\
\hline$\$ 50,000$ & 343 & $56.7(51.7-61.5)$ \\
Not reported & 43 & $7.8(5.4-11.1)$ \\
Highest education level in household & & \\
$\quad$ High school or less & 115 & $18.5(14.8-22.8)$ \\
$\quad$ Some college or more & 502 & $81.5(77.2-85.2)$ \\
Characteristics of county of residence & & \\
Geographic region ${ }^{\dagger}$ & & \\
Western & 107 & $14.3(11.6-17.4)$ \\
Piedmont & 316 & $59.6(55.1-63.9)$ \\
Eastern & 194 & $26.2(22.6-30.1)$ \\
Urbanicity $\dagger^{\dagger}$ & & \\
Urban & 426 & $70.4(65.9-74.5)$ \\
Rural & 191 & $29.6(25.6-34.1)$ \\
\hline
\end{tabular}

Percents may not sum too $100 \%$ due to rounding.

* Does not include parents who indicated they did not know their daughter's school type $(\mathrm{n}=2)$ or that their daughter was not in school $(\mathrm{n}=2)$. Private and home schooled were combined due to the small number of parents reporting their daughters were home schooled $(\mathrm{n}=20)$.

${ }^{\dagger}$ Data collected during Behavioral Risk Factor Surveillance System (BRFSS) survey. All other data collected during Child Health Assessment and Monitoring Program (CHAMP) survey.

Urban defined as within a metropolitan statistical area (MSA) and rural defined as outside of an MSA. 
TABLE 2

Categorical Correlates of HPV Vaccine Initiation Among Daughters $(n=617)$

\begin{tabular}{|c|c|c|}
\hline & $\begin{array}{r}\text { No. Parents Reporting Their } \\
\text { Daughters Had Received } \\
\text { HPV Vaccine/Total No. Parents } \\
\text { in Category (Weighted \%) }\end{array}$ & $\begin{array}{c}\text { Bivariate OR } \\
\quad(95 \% \mathrm{CI})\end{array}$ \\
\hline \multicolumn{3}{|l|}{ Daughter characteristics } \\
\hline \multicolumn{3}{|l|}{ Age (yr) } \\
\hline $10-12$ & 36/198 (18.8) & Ref. \\
\hline $13-15$ & $85 / 235(33.2)$ & $2.14(1.22-3.76)^{*}$ \\
\hline $16-17$ & $77 / 184(45.2)$ & $3.56(1.99-6.37)^{\dagger}$ \\
\hline \multicolumn{3}{|l|}{ Race } \\
\hline Non-Hispanic white & $150 / 450(31.6)$ & Ref. \\
\hline Non-Hispanic black & $26 / 89(32.3)$ & $1.03(0.57-1.88)$ \\
\hline Other & $22 / 78(27.6)$ & $0.83(0.42-1.64)$ \\
\hline \multicolumn{3}{|l|}{ School type } \\
\hline Public & $176 / 544(32.4)$ & $1.65(0.87-3.16)$ \\
\hline Private/home schooled & $20 / 69(22.5)$ & Ref. \\
\hline \multicolumn{3}{|l|}{ Healthcare coverage } \\
\hline No & $5 / 33(16.3)$ & Ref. \\
\hline Yes & $193 / 584(32.1)$ & $2.43(0.71-8.30)$ \\
\hline \multicolumn{3}{|l|}{ Regular healthcare provider } \\
\hline No/don't know & $18 / 90(16.8)$ & Ref. \\
\hline Yes & $180 / 527(33.7)$ & $2.52(1.29-4.91)^{*}$ \\
\hline \multicolumn{3}{|l|}{ Preventive check-up in last 12 mo } \\
\hline No/don't know & $13 / 120(9.4)$ & Ref. \\
\hline Yes & $185 / 497(36.3)$ & $5.53(2.54-12.03)^{\dagger}$ \\
\hline \multicolumn{3}{|l|}{ Received meningococcal vaccine } \\
\hline No/don't know & $52 / 231(18.1)$ & Ref. \\
\hline Yes & $146 / 386(39.3)$ & $2.94(1.84-4.68)^{\dagger}$ \\
\hline \multicolumn{3}{|l|}{ Parent characteristics } \\
\hline \multicolumn{3}{|l|}{ Age $(y r)^{\S}$} \\
\hline$\leq 39$ & $46 / 164(26.4)$ & Ref. \\
\hline $40-49$ & $98 / 303(32.2)$ & $1.32(0.79-2.23)$ \\
\hline 250 & $54 / 150(36.9)$ & $1.63(0.90-2.95)$ \\
\hline \multicolumn{3}{|l|}{ Sex } \\
\hline Female & $168 / 513(31.0)$ & Ref. \\
\hline Male & $30 / 104(32.7)$ & $1.08(0.61-1.93)$ \\
\hline \multicolumn{3}{|l|}{ Marital status $\S$} \\
\hline Married/member of unmarried couple & $142 / 474(29.9)$ & $0.76(0.47-1.25)$ \\
\hline Other (divorced, widowed, separated, never married) & $56 / 143(35.8)$ & Ref. \\
\hline
\end{tabular}

Employment status $\S$ 


\begin{tabular}{|c|c|c|}
\hline & $\begin{array}{r}\text { No. Parents Reporting Their } \\
\text { Daughters Had Received } \\
\text { HPV Vaccine/Total No. Parents } \\
\text { in Category (Weighted \%) }\end{array}$ & $\begin{array}{l}\text { Bivariate OR } \\
\text { (95\% CI) }\end{array}$ \\
\hline Employed for wages/self-employed & $155 / 448(34.8)$ & $1.73(1.04-2.85)^{*}$ \\
\hline Other (unemployed, homemaker, student, retired, unable to work) & $43 / 169(23.6)$ & Ref. \\
\hline \multicolumn{3}{|l|}{ Flu vaccine in the past year (shot or spray) ${ }^{\S}$} \\
\hline No/don't know & $110 / 400(23.9)$ & Ref. \\
\hline Yes & $88 / 217(45.0)$ & $2.60(1.67-4.05)^{\dagger}$ \\
\hline \multicolumn{3}{|l|}{ Pap smear within the last $3 \mathrm{yr} \S \pi$} \\
\hline No & $19 / 56(28.1)$ & Ref. \\
\hline Yes & $128 / 353(34.2)$ & $1.33(0.64-2.76)$ \\
\hline \multicolumn{3}{|l|}{ Any doses of HPV vaccine (mother) ${ }^{\S q l}$} \\
\hline No/don't know & $97 / 284(32.5)$ & Ref. \\
\hline Yes & $13 / 36(33.9)$ & $1.07(0.42-2.70)$ \\
\hline \multicolumn{3}{|l|}{ Frequency children should be seen by healthcare provider for a check-up } \\
\hline Less frequent than once a year/don't know & $11 / 50(27.1)$ & Ref. \\
\hline At least once a year & $187 / 567(31.6)$ & $1.24(0.56-2.76)$ \\
\hline \multicolumn{3}{|l|}{ Household characteristics } \\
\hline \multicolumn{3}{|l|}{ Annual household income $\S^{\S}$} \\
\hline$<\$ 50,000$ & $73 / 231(31.8)$ & Ref. \\
\hline$\$ 50,000$ & $108 / 343(30.3)$ & $0.93(0.59-1.48)$ \\
\hline Not reported & $17 / 43(35.7)$ & $1.19(0.51-2.77)$ \\
\hline \multicolumn{3}{|l|}{ Highest education level in household } \\
\hline High school or less & $38 / 115(36.7)$ & Ref. \\
\hline Some college or more & $160 / 502(30.0)$ & $0.74(0.42-1.30)$ \\
\hline \multicolumn{3}{|l|}{ No. children under age 18 in household $\S$} \\
\hline 1 & $103 / 292(36.3)$ & Ref. \\
\hline$\geq 2$ & $95 / 325(29.3)$ & $0.72(0.48-1.09)$ \\
\hline \multicolumn{3}{|l|}{ Characteristics of county of residence } \\
\hline \multicolumn{3}{|l|}{ Geographic region $\S$} \\
\hline Western & 25/107 (22.9) & Ref. \\
\hline Piedmont & $118 / 316(34.0)$ & $1.74(0.92-3.28)$ \\
\hline Eastern & $55 / 194(29.5)$ & $1.41(0.71-2.82)$ \\
\hline \multicolumn{3}{|l|}{ Urbanicity $\S / /$} \\
\hline Rural & 45/191 (21.3) & Ref. \\
\hline Urban & $153 / 426(35.5)$ & $2.03(1.24-3.34)^{*}$ \\
\hline \multicolumn{3}{|l|}{${ }^{*} P<0.05$} \\
\hline \multicolumn{3}{|l|}{$P<0.001$} \\
\hline
\end{tabular}


II Not asked to all BRFSS respondents.

"Urban defined as within a metropolitan statistical area (MSA) and rural defined as outside of an MSA. HPV indicates human papillomavirus; OR, odds ratio; CI, confidence interval; Ref., referent group. 
TABLE 3

Continuous Correlates of HPV Vaccine Initiation Among Daughters $(n=617)$

\begin{tabular}{|c|c|c|c|}
\hline & \multicolumn{2}{|c|}{ Weighted Mean (Weighted SD) } & \multirow[b]{2}{*}{$\begin{array}{c}\text { Bivariate OR } \\
\quad(95 \% \mathrm{CI})\end{array}$} \\
\hline & $\begin{array}{c}\text { Daughter } \\
\text { Vaccinated } \\
(\mathbf{n}=198)\end{array}$ & $\begin{array}{c}\text { Daughter Not } \\
\text { Vaccinated } \\
(\mathrm{n}=\mathbf{4 1 9})\end{array}$ & \\
\hline \multicolumn{4}{|l|}{ Characteristics of county of residence } \\
\hline Percent aged 5-17 yr & $17.68(1.67)$ & $17.66(1.35)$ & $1.01(0.86-1.20)$ \\
\hline Percent aged 25 and older who are high school graduate (or have higher education) & $79.48(7.77)$ & $78.42(7.31)$ & $1.02(0.99-1.06)$ \\
\hline Percent minority female & $13.80(8.34)$ & $12.43(7.64)$ & $1.02(1.00-1.05)$ \\
\hline Percent who speak a language other than English in the home & $8.66(3.44)$ & $7.82(3.40)$ & $1.08(1.01-1.16)^{*}$ \\
\hline Percent living below federal poverty level & $12.03(4.15)$ & $11.89(3.73)$ & $1.01(0.95-1.07)$ \\
\hline Persons per healthcare professional & $859.63(564.36)$ & $934.64(522.18)$ & $1.00(1.00-1.00)$ \\
\hline 10-yr cervical cancer incidence rate (per 100,000 women) & $8.36(2.13)$ & $8.18(1.80)$ & $1.06(0.94-1.19)$ \\
\hline 10 -yr cervical cancer mortality rate (per 100,000 women) & $2.64(1.09)$ & $2.65(0.93)$ & $0.99(0.78-1.25)$ \\
\hline Teen pregnancy rate (per 1000 females under age 18) & $48.83(13.72)$ & $49.49(11.52)$ & $1.00(0.98-1.02)$ \\
\hline
\end{tabular}


TABLE 4

Multivariate Correlates of HPV Vaccine Initiation Among Daughters $(n=617)$

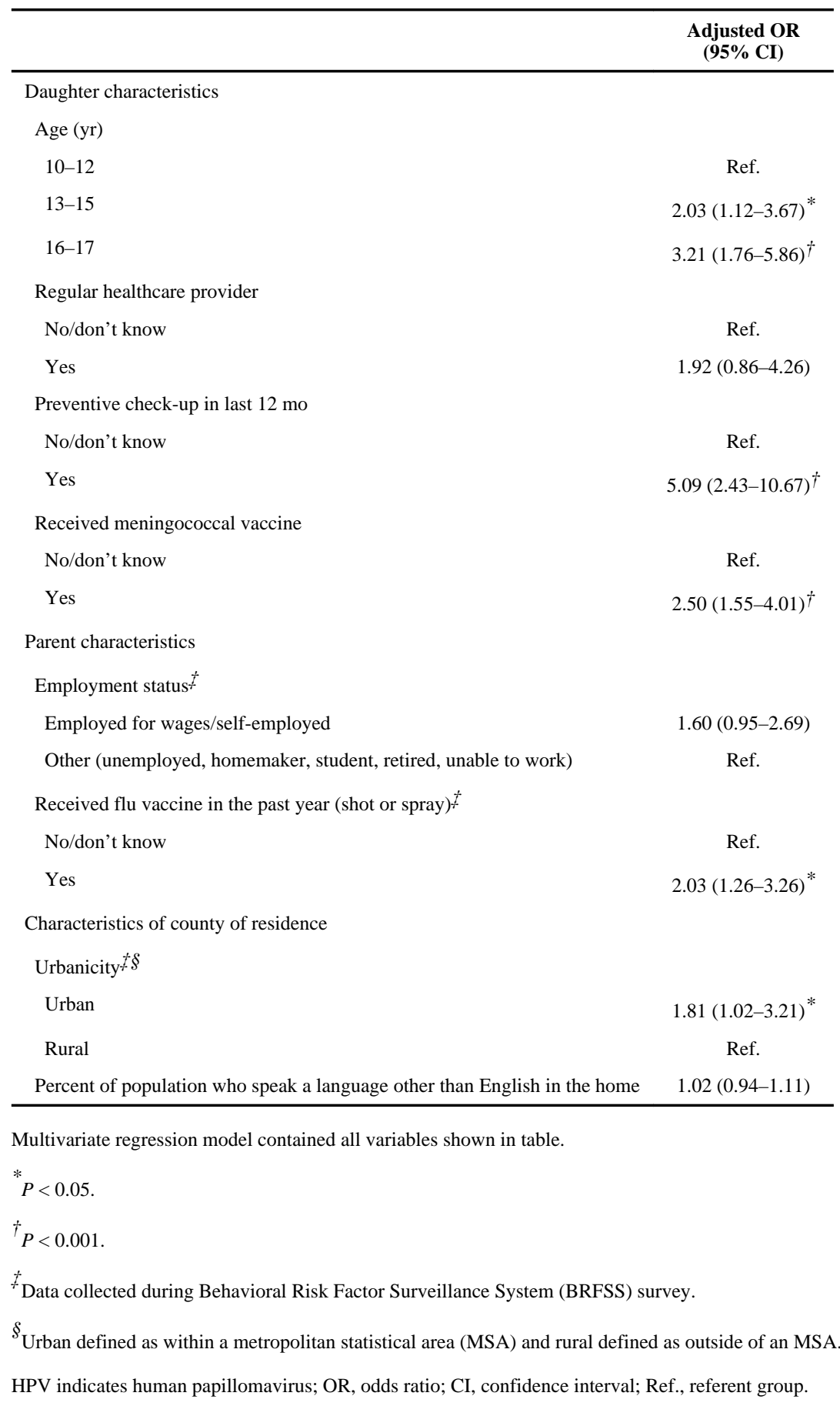

